\title{
An Assessment on Different Solids, Dissolved Oxygen in Industrial Effluents and Its Impact on Public Health
}

\author{
Md Rubel ${ }^{1}$, Md Shahidul Islam*2, Sheik Md Akij ${ }^{3}$ and Mohammad Helal Uddin ${ }^{4}$ \\ ${ }^{1,3}$ Department Of Chemistry, University of Chittagong, Chittagong, Bangladesh \\ ${ }^{2}$ Department of Pharmacy, University of Science and Technology Chittagong (USTC), Bangladesh \\ ${ }^{4}$ Department of Applied Chemistry and Chemical Engineering (ACCE), University of Chittagong, Bangladesh
}

*Corresponding author: Md Shahidul Islam, Department of Pharmacy, University of Science and Technology Chittagong (USTC), Chittagong, Bangladesh

To Cite This Article: Md Shahidul Islam. An Assessment on Different Solids, Dissolved Oxygen in Industrial Effluents and Its Impact on Public Health. Am J Biomed Sci \& Res. 2019 - 5(5). AJBSR.MS.ID.000947. DOI: 10.34297/AJBSR.2019.05.000951.

Received: 㹃 September 12, 2019; Published: 眥 October 14, 2019

\begin{abstract}
Rapid industrialization is adversely impacting the environment globally. The study was carried out to evaluate the biophysical properties of samples contaminated by unplanned industrialization in terms of Effluent Treatment Plant (ETP) efficiency, availability and to evaluate the present scenario of water and air pollution by industrial discharges in order to create public awareness and its impact on public health. The study area was the second largest metropolis of Bangladesh, Chittagong. The study was carried out in 10 industries as a sampling station before and after treatment of industrial discharges and covered mainly two seasons, winter and dry seasons from November 2017 to June 2019. More than six parameters of effluents were analyzed. They are for total dissolved solids, total suspended solids, Total solids, dissolved oxygen, Chemical Oxygen Demand, Biochemical Oxygen Demand test etc. Collection, preservation and analysis of the samples were carried out in accordance with standard procedures. During analysis all precautions were taken in consideration. The ranges of results of waste water obtained were $25-453 \mathrm{mgL}^{-1}$ for total suspended solids (TSS), 2128- 5,573mgL $\mathrm{mor}^{-1}$ total dissolved solids (TDS), 2283-5709 $\mathrm{mgL}^{-1}$ for Total solids, $2.25-7.01 \mathrm{mgL}^{-1}$ for dissolved oxygen, $27-403 \mathrm{mgL}^{-1}$ for Biochemical Oxygen Demand (BOD), 80-1436 $\mathrm{mgL}^{-1}$ for Chemical Oxygen Demand (COD).Here almost all the parameters of industrial discharges are out of range prescribed by the Department of Environment (DoE),Bangladesh which is so much frightening for us. So, the properly untreated industrial discharges mainly heavy metals are deposited in our bodies through food cycle and through inhalation particulate matters which impacts on our body. In this research work, around 100 workers and neighbors of those selected industries has been studied and found to face different health problems like skin problem, vomiting, convulsion, eye irritating problem, headache, loss of IQ, diarrhea, nausea, decrease in memory and other health problems etc.
\end{abstract}

Keywords: Dissolved oxygen; Effluent; Solids; Public health

\section{Introduction}

Bangladesh lies in the northeastern part of South Asia between $20^{\circ} 34^{\prime}$ to $26^{\circ} 38^{\prime}$ North latitude and $88^{\circ} 01^{\prime}$ to $92^{\circ} 41^{\prime}$ East longitude [1]. It is one of the least developed countries with a low resources base under high population pressure, a low land man ratio. Bangladesh is an agricultural country and is now converting to industrial country, but unplanned industrialization creates great impact on our environment degradation. According to world famous medical science related journal "The Lancet", Bangladesh is the most polluted country among the world [2]. In every parameter, the wastewater and industrial emissions of our country is too much higher than acceptable limit which is so much alarming for our existence [3]. Because, wastewater and industrial emissions contain different kinds of hazardous heavy metals, smoke, dust, fume etc. which create great impacts on our health, our eco system as well as

our biodiversity also. Due to unplanned industrialization in terms of Effluent Treatment Plant's (ETP) efficiency and availability, most of the industries in our country have been established randomly here and there. That's why all the industries in our country do not establish Effluent Treatment Plant (ETP) and polluted our environment [4]. Moreover, the industries whose have Effluent Treatment Plant (ETP) do not treat the effluents properly and impacts on our environment as well as public health. The industrial areas in Bangladesh are situated during densely populated regions and the growth of industries has generally been unplanned without keeping the issue of environmental protection in careful consideration. In the production process industries, a lot of solid, semi-solid and liquid wastes are generated that may contain substantial amount of toxic organic and inorganic pollutants, and if dumped in the environment without treatment then this may 
lead to serious environmental consequences [5]. This will also undoubtedly deteriorate soil productivity and adversely affect crop production in the surrounding land area. Industrial effluents had remarkable changes in the distribution of ions and their concentrations in wheat and bean plants [6]. The quality of dissolved minerals in water depends upon the source of water and its path before use [7]. As a consequence, pollution sources increase with the development of cities and it affects the environment in different ways by discharging the large amount of effluent as waste water in the surrounding water bodies, causing the serious problems to environment [8]. Due to deficiency of properly equipped plants and hygienic dumping sites controlled within the necessitated criteria, the industrial wastewater is discharged in an unplanned way to the environment. When the waste flow generally comprises a complex concoction of toxic matters preponderantly natural and synthetic organic contents, metals, and heavy elements, like wise as pathogens from industrial sectors enter into rivers, watercourses and other water bodies, they get dissolved or lie suspended in water bodies or lie suspended in water or get deposited on the bed [9]. This results in the pollution of water whereby the quality of the water deteriorates. Currently, only about $10 \%$ of the effluent generated is being processed; the rest is discharged as it is into our water bodies. Various categories of industries include garments, textile, spinning, pharmaceutical, food manufacturing industry but it is dominated by textile manufacturers, including dyeing and printing units moreover only a few of them have installed effluent treatment plant (ETP). Indiscriminate discharge of liquid waste by the industries has ruined fertility of agricultural land. Industrial liquid wastes have increased the sufferings of the villagers [10]. The DoE identified many polluting industries across the country, which have no treatment facilities for effluents and wastes. These heavily toxic effluents were discharging directly to adjacent soils and rivers [11]. The existing propensity of industrialization and urbanization diminishes the non-renewable resources and interrupts both the soil and surface water quality through promiscuous disposition of industrial effluents, solid wastes and other toxic wastes, which are the major environmental issues posing threats to the existence of human being [12]. Water pollution due to discharge of untreated industrial effluents into water bodies is a major problem in the global context [13]. The problem of water pollution is being experienced by both developing and developed countries. Human activities give rise to water pollution by introducing various categories of substances or waste into a water body [14]. The more common types of polluting substances include pathogenic organisms, oxygen demanding organic substances, plant nutrients that stimulate algal blooms, inorganic and organic toxic substances [15].

\section{Materials and Methods}

The study was carried out through experimental method. The sample was analyzed through experiment. Effluents from different industrial area, Chittagong and was compared with the standard level of wastewater quality parameters of DOE. Experimental data was collected and processed very carefully, and the experiments were performed at least three times to minimize analytical error.

\section{Used Instruments}

Water samples were analyzed for total dissolved solids (TDS) (by Combo meter) and metal test (by Hach DR 5000 metal test meter). Collection, preservation and analysis of the samples are carried out in accordance with standard procedures.

\section{Study Area}

Chittagong, the second largest metropolis of Bangladesh and the economic gateway of the country, is situated on the right bank of the river Karnaphuli. In this research work, nine sampling industries have been selected to collect the wastewater for laboratory analysis. Samples were collected from inlet wastewater and outlet water of different industries. A large amount of industrial effluent is discharged from different industries. During analysis all precautions were taken in consideration. The study was carried out in 10 industries as a sampling station before and after treatment of industrial discharges and covered mainly two seasons, winter and dry seasons between November 2017 to June 2019.

\section{Sampling Techniques}

Samples were collected in $100 \mathrm{ml}$ Plastic bottles. All samples for laboratory analysis had been pre-washed with $10 \%$ nitric acid and rinsed with distilled water before use. Each bottle was rinsed three times with the appropriate amount of sample before final sample collection. For heavy metal $90 \mathrm{ml}$ of effluent samples from each sampling point was transferred to $100 \mathrm{ml}$ plastic bottles. These samples were placed in a lightproof box to protect from direct sunlight and then taken to the laboratory for analysis. To provide necessary information for each sample, date of collection, location etc. were recorded in the notebook and each sample collected in a plastic bottle was labeled separately with a unique identification number. Effluent samples were then filtered through filter paper (Whatman No. 42) to remove undesirable solid and suspended materials. In the laboratory, the bottles were kept in a clean, cool, dark and dry place. The chemical analyses of effluent were performed as quickly as possible on arrival at the Laboratory of DoE.

\section{Dissolved Oxygen (D0)}

The DO meter was calibrated before every measurement using $2 \% \mathrm{Na}_{2} \mathrm{SO}_{3}$ solution (MK Mohanta et al. 2010). DO was measured immediately after collection of each sample within 5-10 minutes at the sampling spot by using DO meter.

\section{Biochemical Oxygen Demand (BOD5)}

The sample was taken in the bottle and diluted with the water. The probe of the multimeter was placed inside the bottle and the 
reading was taken and finally the bottle was placed inside the refrigerator at $200^{\circ} \mathrm{C}$ of temperature for 5 days. After 5 days, the data was taken again trough the multi meter and the result was obtained.

$$
\text { BOD= Initial DO - Final DO }
$$

\section{Chemical Oxygen Demand (COD)}

Turned on the reactor and preheated to $150^{\circ} \mathrm{C}$. Hold the vial at 45 -degree angle and $2 \mathrm{ml}$ of sample. Then the sample was mixed by inverting the vial. The sample was heated for two hours with a strong oxidizing agent. After the vial was placed inside, the spectrophotometer and compared it with the blank vial. Thus, the result was obtained.

\section{Total Dissolved Solid (TDS)}

TDS were measured after collection of samples within 5-10 minutes at the sampling spot by using Combo meter.

\section{Total Solid (TS) and Total Suspended Solid (TSS)}

$100 \mathrm{ml}$ of water sample was taken in a beaker or glass dish and evaporated to dryness in an oven at $103-105^{\circ} \mathrm{C}$ then cooled in a desiccator and weighed.

$$
\text { Total solids }(\mathrm{ppm})=\frac{m g \text { of total solid } \times 1000}{m l \text { sample }}
$$

Total suspended solids $=$ Total solids - Total dissolved solids mg of total solid x $1000 \mathrm{ml}$ sample

\section{Total Dissolved Solids (TDS)}

The sample water was taken in the beaker and the probe of the multimeter was placed inside the beaker for few minute. The static result shown on the screen of the multimeter was the TDS of the water.

\section{Results and Discussion}

This chapter presents the results of analysis and findings of effluent quality parameters of water pollution. Wastewaters are the principal sources of surface and ground water contamination. To evaluate the pollution content thirteen samples from different industries were analyzed for various physical and chemical parameters. The chemical parameters of water from the industries obtained from the analyses are presented and comparison of different parameters of standard values with existing values is presented. Water quality for agriculture is tremendously mentionable because it has a remarkable impact on soil, crop and human life. Therefore, it is necessary to determine the quality of wastewater and air samples and its possible effects due to longterm irrigation as well as public health.

\section{Total Dissolved Solid (TDS)}

Comparison of ETP outlet water TDS values with standard

\section{(Figure 1a \& 1b)}

Reasons and Comments: TDS is the measure of extent of solid materials dissolved in water. Total dissolved solids (TDS) usually affect the refractive capacity of the water body. If the TDS level is high, especially due to dissolved salts, many forms of aquatic life are affected. TDS values of the different sampling points were ranged from 2128 to $5573 \mathrm{mg} / \mathrm{L}$ (Table 6). The highest TDS value was observed at the Confidence Salt Factory ltd and the lowest at the Unilever Kalurghat Factory. All the other analyzed samples possess a higher value of TDS than the standard value of DoE. Water that contains less than $500 \mathrm{mg} / \mathrm{L}$ of dissolved solid is generally satisfactory for the domestic use and other industrial purposes. Water that contains more than $1000 \mathrm{mg} / \mathrm{L}$ of dissolved solids usually contains minerals that give it a distinctive taste or make it unsuitable for human consumption. A maximum TDS value of 400 $\mathrm{mg} / \mathrm{L}$ is permissible for diverse fish production.

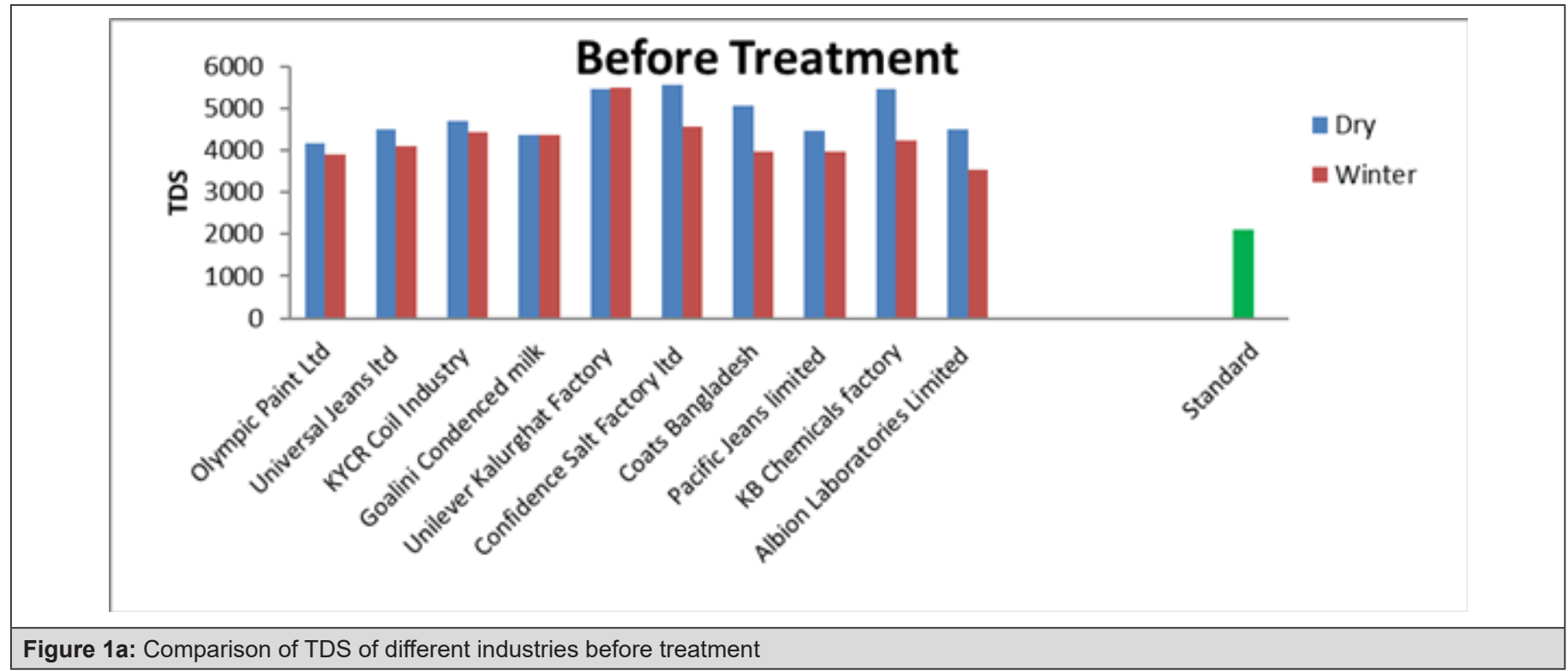




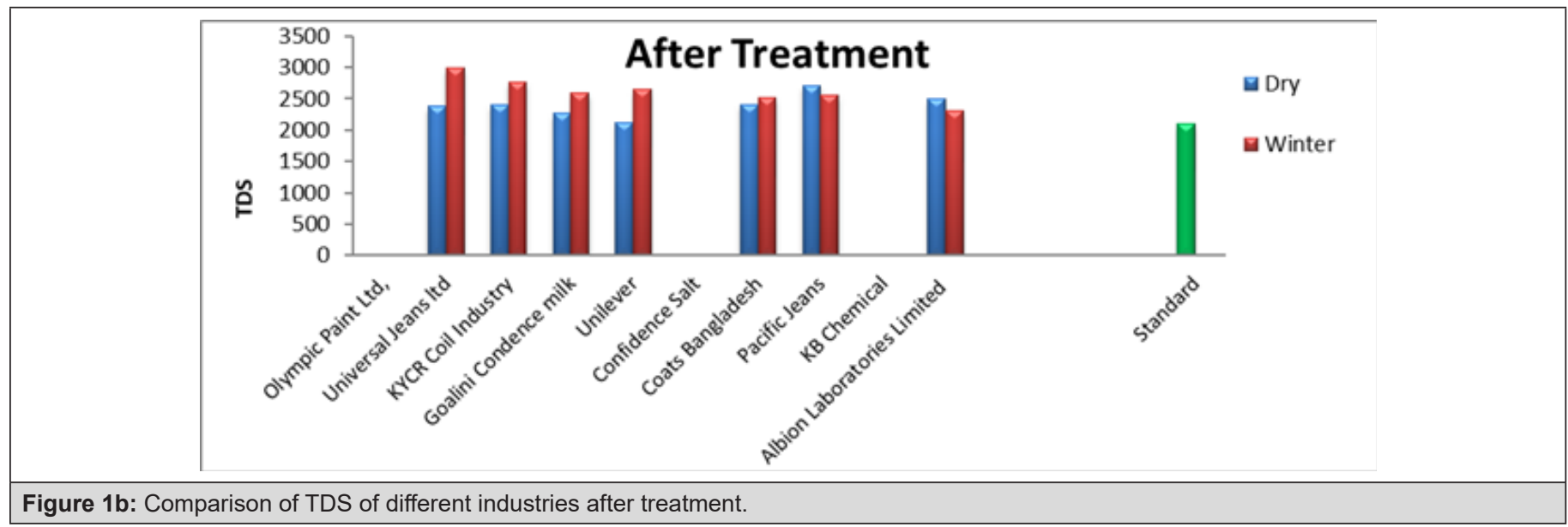

Table 1: Answers of the questionnaire.

\begin{tabular}{|c|c|c|}
\hline SI No. & Health Problems & $\%$ of Affected Workers and Neighbors \\
\hline 1 & $\begin{array}{l}\text { Gastrointestinal System: Nausea, Vomiting, } \\
\text { Diarrhoea, Abdominal ache, Metallic Taste }\end{array}$ & $70 \%$ \\
\hline 2 & $\begin{array}{l}\text { Respiratory System: Chronic cough, Asthma, } \\
\text { Shortness of breath, Chest pain }\end{array}$ & $40 \%$ \\
\hline 3 & $\begin{array}{l}\text { Musculo-Skeletal pain: Chronic muscle pain, } \\
\text { Joint pain }\end{array}$ & $43 \%$ \\
\hline 4 & $\begin{array}{l}\text { Pschycological: Anxiety, Depression, Insomnia, } \\
\text { Loss of memory }\end{array}$ & $76 \%$ \\
\hline 5 & $\begin{array}{c}\text { Nephrological: Burning urination, Inconsistence, } \\
\text { Scanty urine }\end{array}$ & $37 \%$ \\
\hline 6 & Skin: Rash, Allergy, Excessive Sweating & $82 \%$ \\
\hline 7 & Eye: Pain eyes, Burning eyes, Watering & $57 \%$ \\
\hline 8 & Neurological: Convulsion & $19 \%$ \\
\hline
\end{tabular}

\section{Total Suspended Solid (TSS)}

\section{Comparison of ETP outlet water TSS values with standard} (Figure 2a \& 2b)

Reasons and Comments: Suspended solid do not mean that they are floating matters and remain on top of water layer. They are under suspension and remain in water sample. Total suspended solids play an important role in water and wastewater treatment. Their presence in water sample causes depletion of oxygen level. Total suspended solids (TSS) are the filterable particles in water.
It may be of organic origin like algae, zooplankton and bacteria or inorganic origin like clay, silt, calcium, bicarbonates, chloride etc. Total suspended solids (TSS) reduce light penetration, hence reducing the ability of algae to photosynthesize. TSS values of the different sampling points were ranged from 25 to $453 \mathrm{mg} / \mathrm{L}$ (Figure $2 \mathrm{a}, 2 \mathrm{~b})$. The highest TSS value ( $453 \mathrm{mg} / \mathrm{L}$ ) was observed at the KB Chemicals Factory due to may be presence of different suspended metals in that soap factory. All the other analyzed samples possess a higher value of TSS than the standard value of DoE. TSS is indirectly controlled by the limits on turbidity.

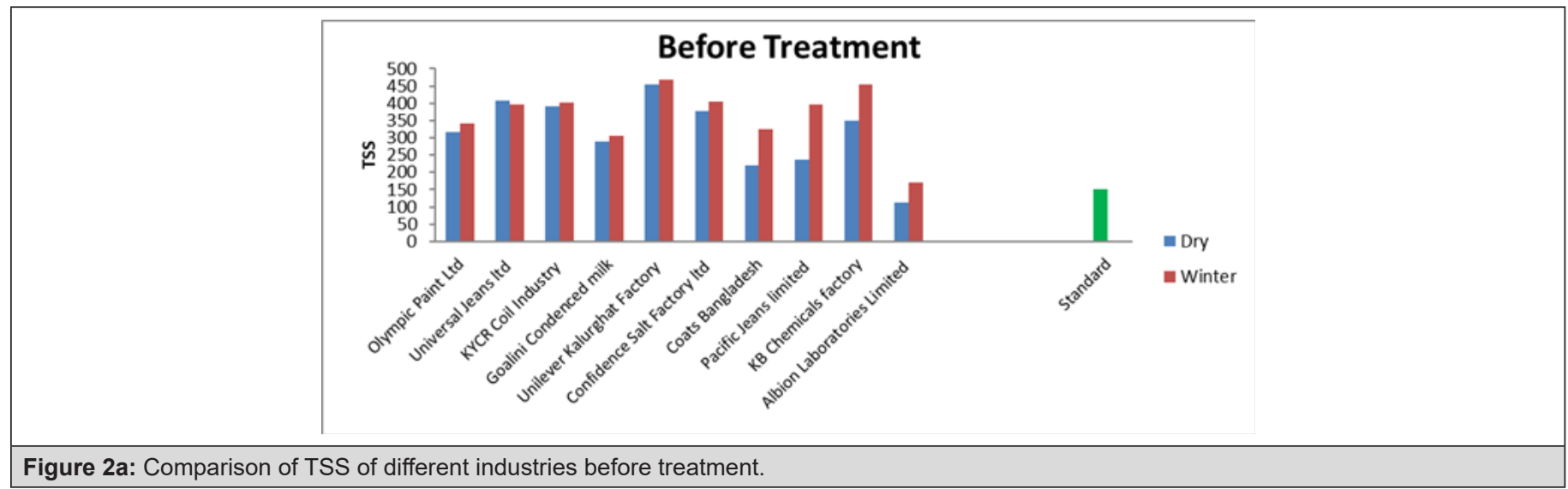




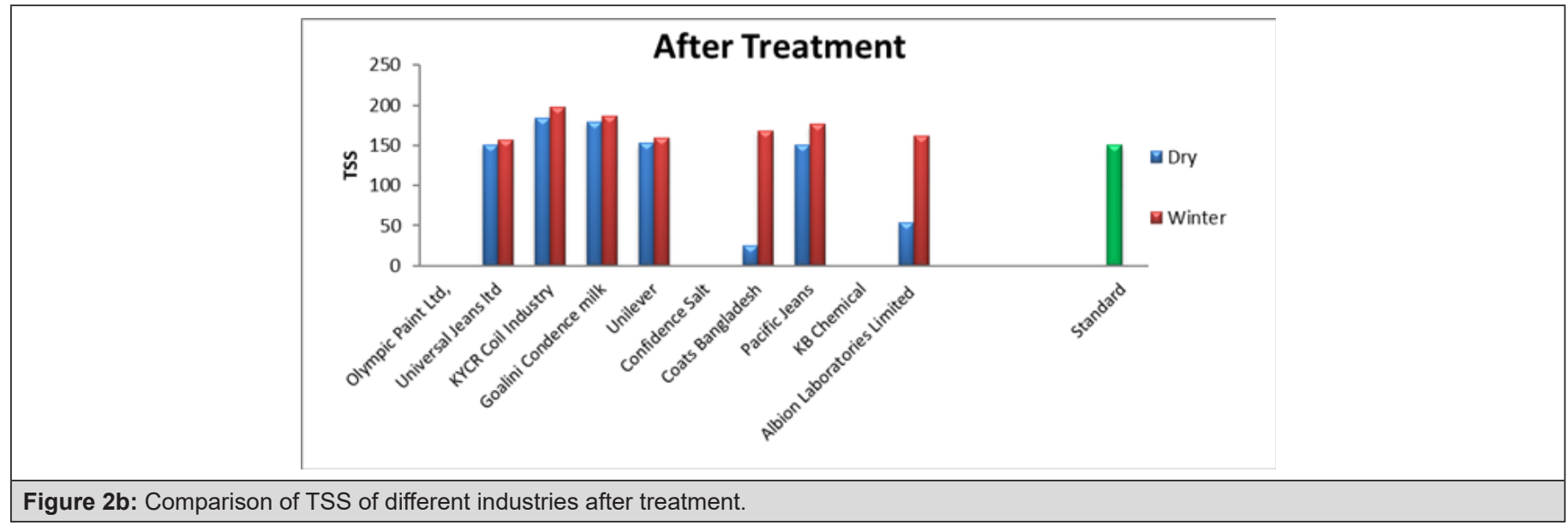

\section{Total Solids (TS)}

Comparison of ETP outlet water TS values with standard (Figure 3a \& 3b)

Reasons and Comments: From the above Figure 3a and 3b, it is observed that after treatment almost every sampling industry contains high TS values which were not within the permissible limit $\left(2250 \mathrm{mgL}^{-1}\right)$ of DoE. This is because, almost every industry uses different metals containing substances which are mixing with the effluents and that's why TS values of different industries will be increased. Here TS was found positively correlated with TSS. As usual, there is no significant variation between dry and winter season due to industrial indoor analysis of sample (Figure $3 \mathrm{a}, 3 \mathrm{~b}$ ).

Comments: As we know that TS can be obtained by TSS plus TDS which are also reflected from the Figure 8.c and 8.d. Even after treatment, almost every sampling industry contains high TS, TDS and TSS values which were not within the permissible limit of DoE.
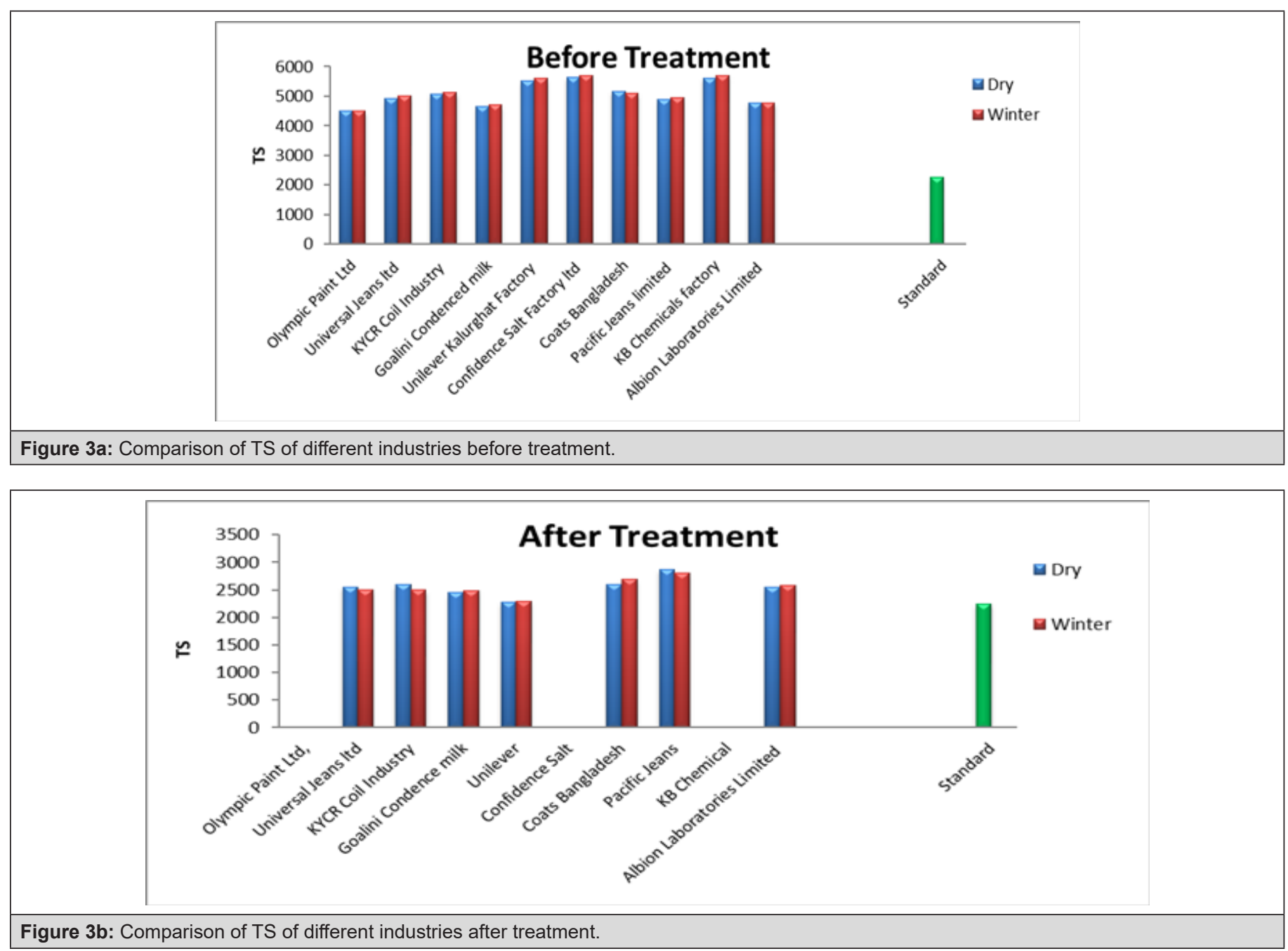


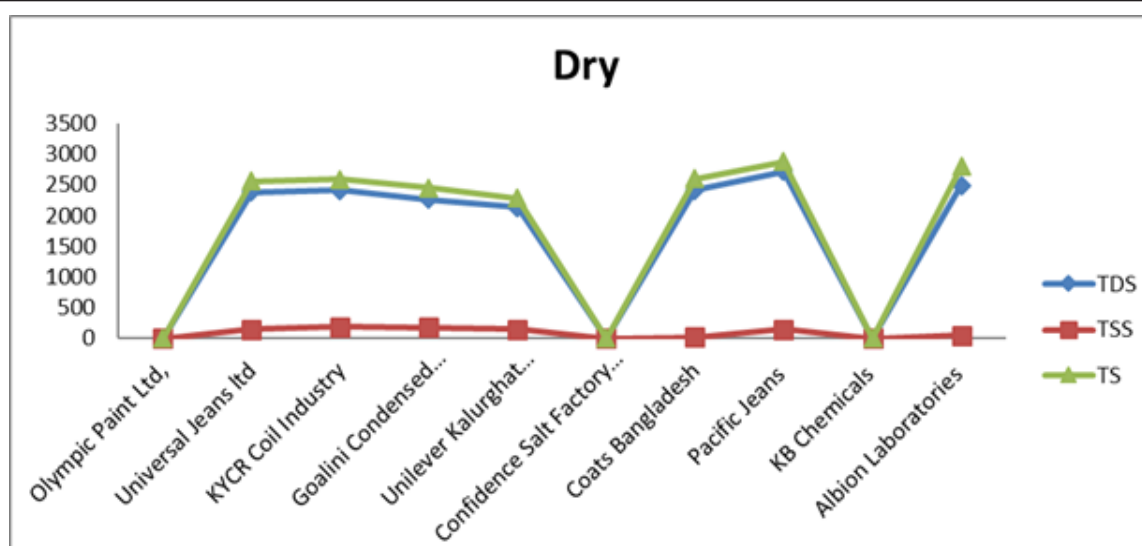

Figure 3c: Comparative measurement of TDS, TSS and TS in dry season, after treatment.

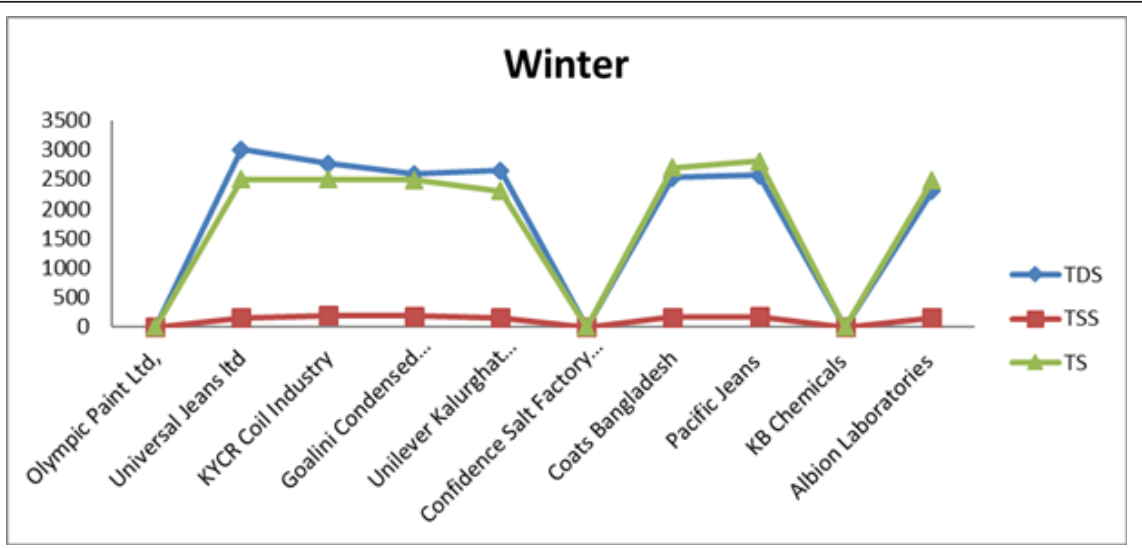

Figure 3d: Comparative measurement of TDS, TSS and TS in winter season, after treatment.

\section{Dissolved Oxygen (DO)}

Comparison of ETP outlet water DO values with standard

\section{(Figure 4a \& 4b)}

Reasons and Comments: Oxygen enters the water through photosynthesis in aquatic plants or from the transfer of oxygen between the air and water by waves, turbulence, currents, etc. Fastmoving water, lower temperature, and lower salinity all also result in the availability of more DO. The DO of all collected effluent samples was within the range from 2.25 to $7.01 \mathrm{mg} / \mathrm{L}$. Here, the DO level $(2.25 \mathrm{mg} / \mathrm{L})$ of Olympic Paint industry is too low than acceptable limit of DoE which is so alarming for aquatic existence. Because, DO levels below $1 \mathrm{mg} / \mathrm{L}$ will not support fish; below $2 \mathrm{mg} / \mathrm{L}$ may lead to the death of most fishes. DO content should be above 6.0 $\mathrm{mg} / \mathrm{L}$ for drinking water and more than $5.0 \mathrm{mg} / \mathrm{L}$ is suggested for fisheries and irrigation [6]. Adequate dissolved oxygen is necessary for good water quality. Oxygen is a necessary element to all forms of life.

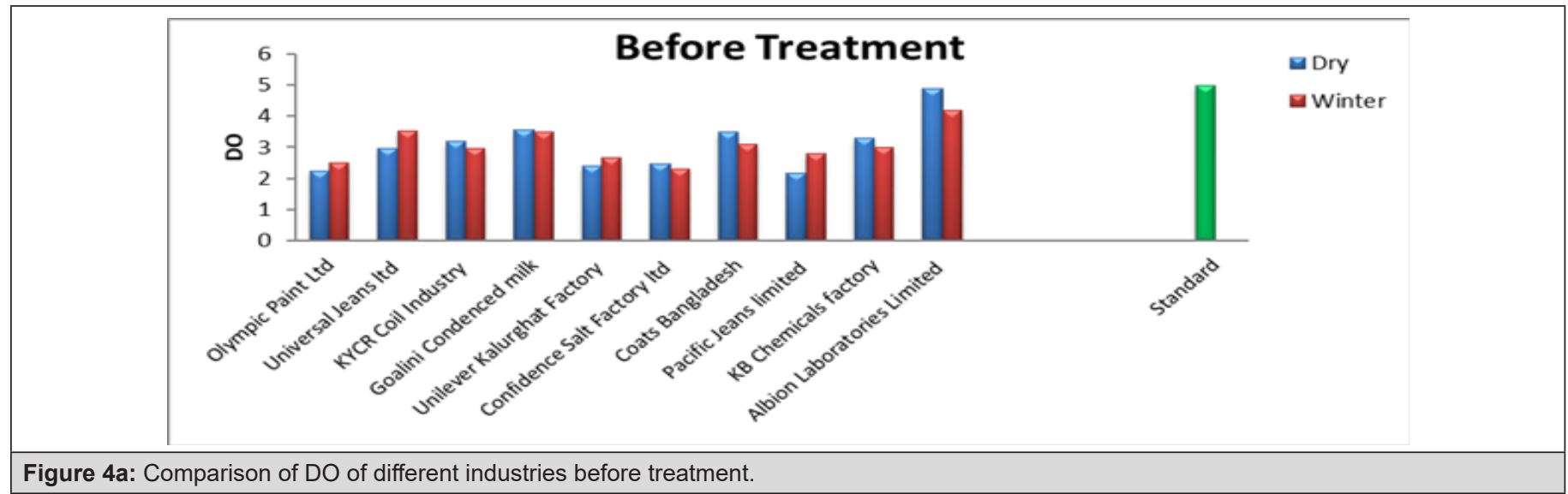




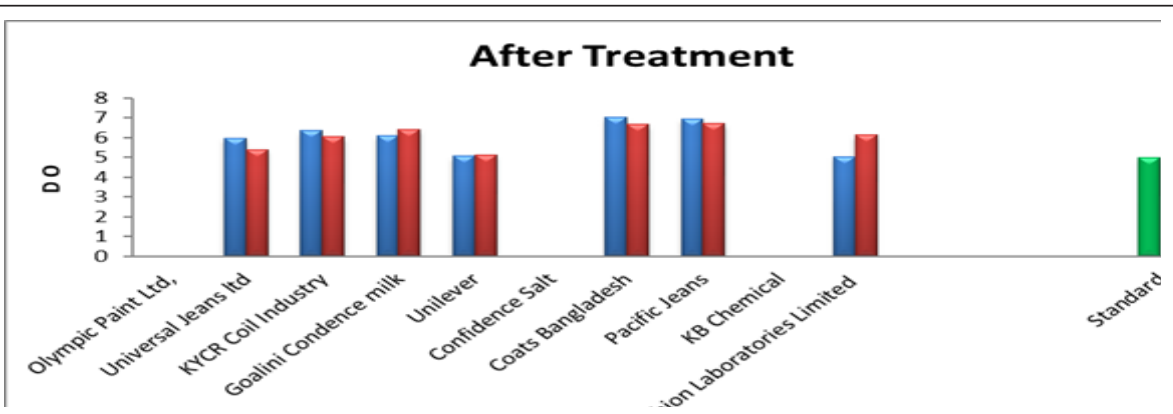

Figure 4b: Comparison of DO of different industries after treatment.

\section{Biological Oxygen Demand (BOD)}

Comparison of ETP outlet water BOD values with standard (Figure 5a \& 5b)

Reasons and Comments: Biochemical oxygen demand (BOD) is a measure of the oxygen requirement for the biochemical degradation of organic materials and the oxygen used to oxidize inorganic materials such as sulfides, ferrous ions and reduced forms of nitrogen. We know DO is inversely proportional to BOD. So, when DO level decreases then BOD will be increased and different types of microorganism will be formed, that's why water gets polluted. From the Table 11, we observe that the discharging effluents of almost every industry contains high BOD level which ranges from 27 to $403 \mathrm{mg} \mathrm{L}^{-1}$.

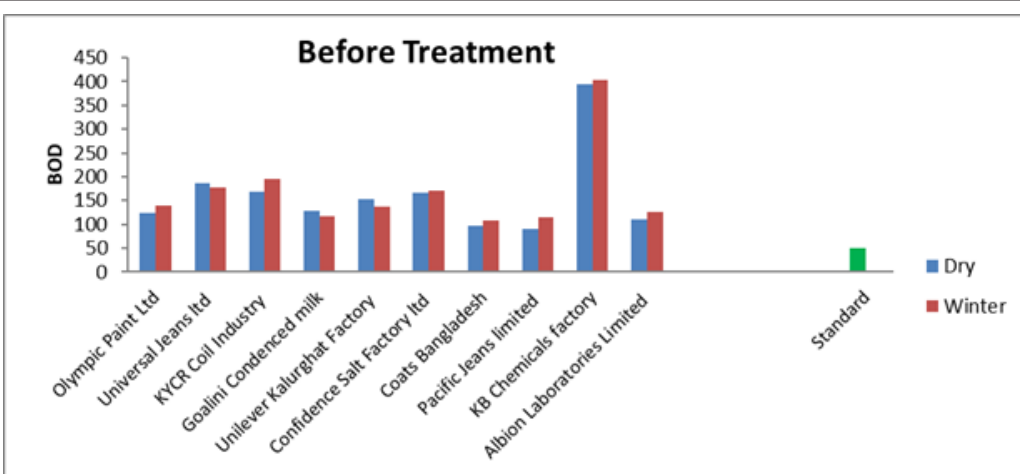

Figure 5a: Comparison of BOD of different industries before treatment.

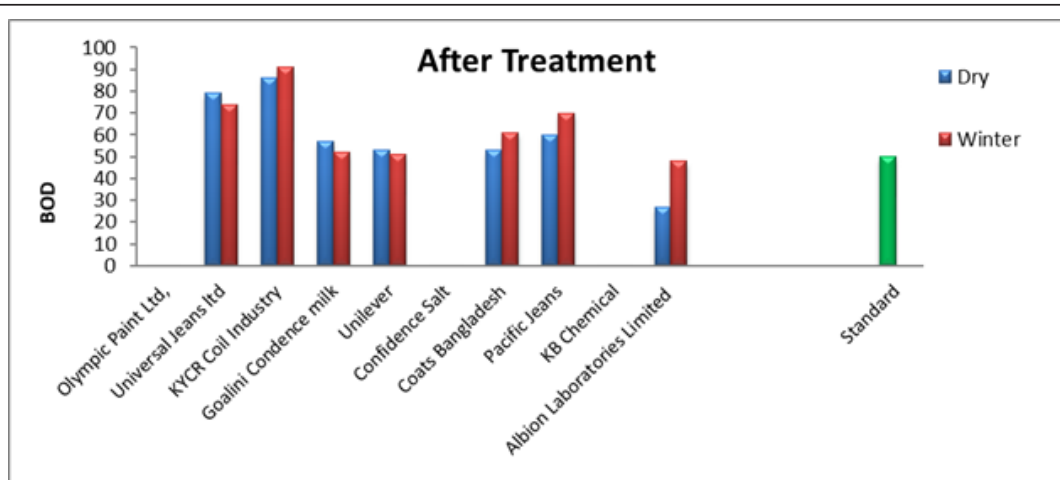

Figure 5b: Comparison of BOD of different industries after treatment.

\section{Chemical Oxygen Demand (COD)}

Comparison of ETP outlet water COD values with standard (Figure 6a \& 6b)

Reasons and Comments: Chemical oxygen demand (COD) measures the organic portion susceptible to oxidation by a strong chemical oxidant. So, effluents contain different types of chemical substances which can be oxidized, and COD will be increased, that's why, water gets polluted. Here, The COD of all collected effluent samples were within the range from 80 to $1436 \mathrm{mg} / \mathrm{L}$. Here the COD level (1436 mg/L) of KB Chemicals Factory is too high than acceptable limit (200 mg/L) of DoE due to presence of different chemicals which is so alarming for aquatic existence. Variations in inlet COD is due to the chemical consumption of industries is varies according to their process requirement. Here COD was found positively correlated with o-phosphate-P and sulphate-S (Figure 6c $\& 6 d)$. 

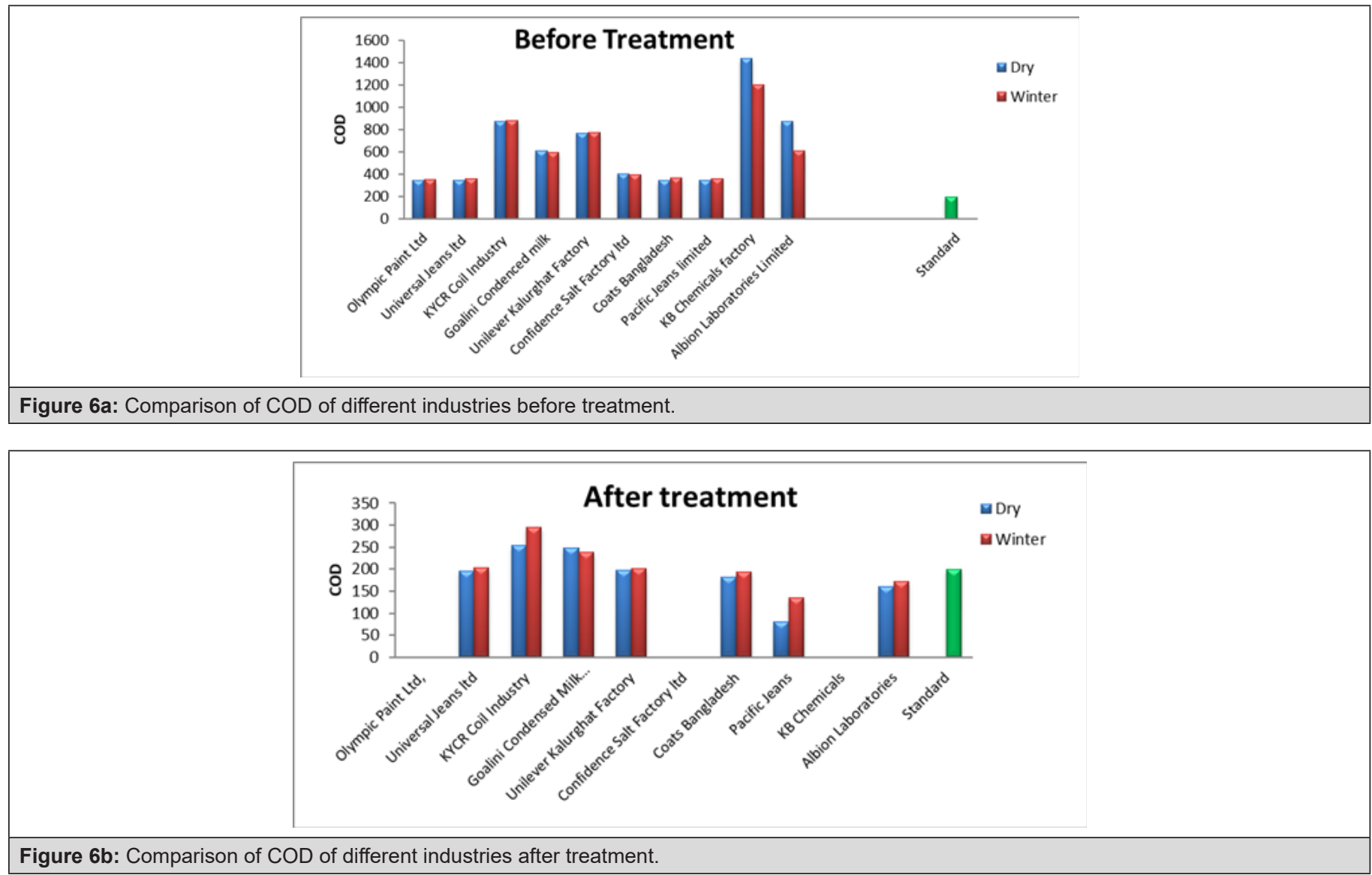

Comments: All the industrial samples had dissolved oxygen less than the DoE standard value of $5 \mathrm{mg} / \mathrm{L}$. So, it is assumed that wastewater from all the industries has high level of biodegradable matter and microorganisms. The Figure $6 c$ \& $6 d$ show that the comparative measurement of COD, BOD and DO in winter season and dry season, after treatment. Here, DO values are low, that's why, BOD and COD values are too high in different industries due to presence of different types of chemicals and microorganism in water.

\section{Health Problems of industrial effluents and emissions}

Pollution is the largest environmental cause of disease and premature death in the world today. Diseases caused by pollution were responsible for an estimated 9 million premature deaths in $2015,16 \%$ of all deaths worldwide, three times more deaths than from AIDS, tuberculosis, and malaria combined and 15 times more than from all wars and other forms of violence. In the most severely affected countries, pollution-related disease is responsible for more than one death in four [2].

\section{Number of Percentage of Workers and Neighbors}

\section{Affected by Effluents}

In this study, 100 workers and neighbors of that selected industries were under investigation from November 2015 to June 2019 aged between 18 to 60 years were enumerated and they informed, they must face frequently following health problems due to industrial degradation. It was descriptive type of crosssectional study with one step satisfaction. It was an open question on predominant health problems in the selected industries. The respondents mentioned that skin diseases, diarrhea, gastric ulcers, and respiratory illnesses like common cold, asthma were the most common health problems amongst the workers and neighbors in the area. In addition, people also suffer from indigestion, hypertension, conjunctivitis, pneumonia, malaria, tuberculosis etc. Most of the people (age between 41 to 60 years) involved in this study reported that they were suffering from mainly skin diseases, diarrhea, gastric ulcers or other gastric problems at the time that the research was taking place (Table 1 ).

\section{Questionnaire}

1. Name of the industry.

2. Age range of the workers and neighbors

a. 18 - 40 years b. $41-60$ years

3. Health problems regarding Gastrointestinal System

a. Yes b. No

4. Health problems regarding Respiratory System

a. Yes b. No 
5. Health problems regarding Musculo-Skeletal pain

a. Yes b. No

6. Health problems regarding Pschycological

a. Yes b. No

7. Health problems regarding Nephrological

a. Yes b. No

8. Health problems regarding Skin

a. Yes b. No

9. Health problems regarding Eye

a. Yes b. No

10. Health problems regarding Neurological

a. Yes b. No

\section{Conclusion}

From this research work it is observed that all the industries in Bangladesh donotestablish the ETP section.In many of the industries, effluent treatment is not up to the mark and are not checked frequently by the factory authority, Department of Environment or Concerned bodies. Another vital problem experienced by different factories with ETPs are inadequate treatment due to inappropriate, inaccurate dosing of chemicals needed in the treatment process and the compliance and enforcement of these regulatory measures are not optimum and satisfactory. The other problems experienced by different industries; many industries start their ETP plant just before entering the monitoring officers of DOE in their factory. It is highly recommended that sloppy disposal of the effluents should be strongly prohibited, discouraged and there is need for each industry to install an effluent treatment plant and its proper implementation with a view to treat wastes before being discharged. Right now, there is very much required for DOE (Department of Environment), BEMA (Bangladesh Environment Management Authority) and concern bodies to closely monitor the effluents from industries. So, in these situations only practicable alternatives that must be maintained are dumping location should be properly managed to minimize its effects on the environment, proper laws should be strongly preserved and maintained, suitable distance from the surrounding water body should be maintained, appropriate laws on dumping of industrial effluents should be set up as well as some lessening measures should be taken for example, alertness should be also built up among the people about the environment degradation due to the discharging of industrial effluents. Our mass media should also come forward to aware people against this environment degradation. So, formal and informal methods of education might be adopted through local media, seminars, celebrations, workshops, walks and student competitions to aware the people regarding the process of environment degradation.

\section{References}

1. Ahmed AU, Reazuddin (2000) Industrial pollution of water systems in Bangladesh. University press Limited, Dhaka, Bangladesh. pp. 175-178.

2. Philip J Landrigan, Richard Fuller, Nereus J R Acosta, Olusoji Adeyi, Robert Arnold et al. (2017) The Lancet Commission on pollution and health. 391(10119): 462-512.

3. Salam H Bauer, K Kassin, S M Ullah, H Puxbaum (2003) Aerosol Chemical Characteristics of a Mega-City in Southeast Asia (Dhaka, Bangladesh). Atmospheric Environment 37(18): 2517-2528.

4. D J Dockery, CA Pope (1994) Acute Respiratory Effects of Particulate Air Pollution. Ann Rev Public Health 15: 107-132.

5. Agarwal RR, Yadav JP, Gupta RN (1982) Saline and Alkali Soils of India. Indian Council of Agricultural Research, New Delhi, India. pp. 223-228.

6. EQS (Environmental Quality Standard) (1997): Bangladesh Gazette, Registered nr. DA-1, Ministry of Environment, Government of Bangladesh.

7. Ahmmed KM Tanvir, Begum D A(2010) Air Pollution Aspects of Dhaka City, Proc. of International Conference on Environmental Aspects of Bangladesh (ICEAB10).

8. Begum RA (2006) Assessment of water and soil pollution and its effect on rice. Ph.D Thesis, Department of Agricultural Chemistry, Bangladesh Agricultural University, Mymensingh.

9. Chhatwal GR (1998) Encyclopedia of Environmental Biology. Anmol. Pub. Pvt. Ltd., New Delhi, India, 2: 287-301.

10. Bhuiyan MAH, Suruvi NI, Parnpare SB, Islam MA, Quraishi SB, et al. (2010) Investigation of the possible sources of heavy metal contamination in lagoon and canal water in the tannery industrial area in Dhaka Bangladesh. Environmental Monitoring and Assessment 175(1-4): 633649.

11. B A Begum (2016) Dust Particle (PM10 and PM2.5) Monitoring for Air Quality Assessment in Naryanganj and Munshiganj, Bangladesh. 25(1\&2): 45-47.

12. Clesceri L S, Greenberg A E, Eaton A D (1998) Standard methods for the examination of water and wastewater. Washington: American Public Health Association-American Water Works Association- Water Environment Federation.

13. EB Larson (2004) Biodegradability of hydrocarbon contaminants during natural attenuation of contaminated groundwater determined using biological and Chemical Oxygen Demand, Master's Thesis Presented to the Faculty of California Polytechnic State University San Luis Obispo.

14. AHMJ Alobaidy, MA Al Sameraiy, AJ Kadhem, A Abdul Majeed (2010) Evaluation of Treated Municipal Wastewater Quality for Irrigation. Journal of Environmental Protection 1(3): 216-225.

15. G M Jahangir Alam (2009) Environmental Pollution of Bangladesh - It's Effect and Control. International Conference on Mechanical Engineering. 